\title{
Spiderweb smokescreens: spider trickster uses background noise to mask stalking movements
}

\author{
R. STIMSON WILCOX*, ROBERT R. JACKSON†\& KRISTEN GENTILE* \\ $*$ D epartment of Biological Sciences, Binghamton U niversity \\ tD epartment of Z oology, U niversity of C anterbury
}

( Received 24 February 1994; initial acceptance 28 M ay 1994;

final acceptance 6 J une 1995; M S. number: A6932)

\begin{abstract}
A bstract. The stalking behaviour of four species of jumping spiders, Portia fimbriata, P. labiata, $P$. schultzi and P.africana, was examined to determine whether Portia opportunistically exploits situations in which the prey spider is distracted by environmental disturbances. Disturbances were created mainly by wind blowing on webs and a magnet shaking webs. All four Portia species moved significantly further during disturbance than during non-disturbance, a behaviour labelled 'opportunistic smokescreen behaviour'. Portia can discriminate between spiders and other prey such as live insects, wrapped-up insects in the web, and egg sacs, because Portia used opportunistic smokescreen behaviour only against spiders and not against these other types of prey. If the location of disturbances and the location of prey differ, Portia can accurately discriminate between them. P ortia's smokescreen behaviour apparently is a true predatory tactic because Portia attacked prey more often during disturbances than at other times. Smokescreen behaviour appears to work in part because the disturbances that P ortia uses for smokescreens interfere with the prey's ability to sense P ortia's stalking movements.

(C) 1996 The A ssociation for the Study of A nimal Behaviour
\end{abstract}

Predators use three main techniques to get near to their prey before attacking: stalking the prey, luring the prey in from ambush and passively waiting in ambush (reviewed in Curio 1976). Predators that use deceitful signals when stalking or luring from ambush have been called 'aggressive mimics' (reviews in Wickler 1968; M itchell \& Thompson 1986), and they include such wellknown examples as firefly 'femmes fatales' (Lloyd 1986) and angler fish (Pietsch \& G robecker 1978).

In this paper we investigate the aggressive mimicry behaviour of Portia, a genus of jumping spiders. Like all jumping spiders, P ortia has acute vision (Blest 1985; L and 1985). Typical jumping spiders are primarily cursorial hunters of insects (Forster 1982). Jumping spiders of the genus Portia are distinctive, however, because they specialize in preying on other spiders and because they are strikingly versatile aggressive mimics that

Correspondence: R. S. Wilcox, D epartment of Biological Sciences, Binghamton U niversity, Binghamton, NY 13902-6000, U.S.A. (email: fac273@bingvmb.cc. binghamton.edu). R. A. Jackson is at the Department of Zoology, University of Canterbury, Christchurch 1 , $\mathrm{N}$ ew Zealand. use a large repertoire of web-borne vibratory signals, emphasizing different signals when pursuing different prey spiders (J ackson \& Blest 1982; J ackson \& H allas 1986; Jackson \& W ilcox 1990), and determining which signals to use with some prey spider species by a flexible trial and error method (J ackson \& Wilcox 1994).

Portia makes signals in two contexts when on other spiders' webs: (1) standing on the web and luring the spider in with signals that apparently imitate a struggling insect; (2) signalling while visually stalking across the web toward the prey spider on the web (reviewed in Jackson 1992). While studying Portia's aggressive mimicry, we found that Portia appears to stalk prey spiders more rapidly when the prey's vibratory senses are subjected to background noise, such as when wind blows on their webs. We call this behaviour of Portia opportunistic 'smokescreen behaviour'.

The present paper is a laboratory study of Portia's smokescreen behaviour. We provide experimental evidence demonstrating that Portia opportunistically responds to environmental noise in a variety of circumstances, is discriminating in its use of smokescreen behaviour, and attempts 
more captures of prey spiders during background disturbance than during periods of quiet. We also present evidence showing that smokescreen behaviour works in part because background noise interferes with the prey's ability to sense Portia's stalking movements.

\section{GENERAL METHODS}

Throughout this study we used standard spider laboratory maintenance procedures, cage designs and terminology described in Jackson \& Hallas (1986).

We conducted tests on four of the eight known species of Portia: P. fimbriata (populations from Queensland and Northern Territory, A ustralia, and from Sri Lanka); P. labiata (Sri Lanka); $P$. schultzi (K enya); and P. africana (K enya). We list below the spiders used for prey, where they were collected, and pertinent characteristics of the webs they build. (1) A rgiope appensa (A raneidae): Queensland, A ustralia; orb web. (2) Z osis genicularis (Uloboridae): Queensland; orb web. (3) H ygropoda dolomedes (Pisauridae): Queensland; horizontal sheet web in the upper dihedral of single large leaves. (4) Badumna longinquus (A maurobiidae): N ew Zealand; sheet web. (5) A chaearanea sp. (Theridiidae): $\mathrm{N}$ ew Zealand; space web. (6) A chaearanea krausi: Queensland; space web; hangs a curled leaf in web for a shelter. (7) A rgyrodes flavipes (Theridiidae): Queensland; space web under leaves. (U nlike the better-known kleptoparasitic species of A rgyrodes, A. flavipes lives exclusively in its own web: R. R. Jackson, unpublished data.) (8) Pholcus phalangioides (Pholcidae); New Zealand; space web. (9) Philoponella variabilis (U loboridae): Q ueensland; social species; individual orb webs that break down into a communal space web when the number of spiders is large (R . R . J ackson, unpublished data). Before tests we removed all $P$. variabilis from webs except one individual, to eliminate confusion in P ortia as to which spider to stalk. (10) Stegodyphus sarasinorum (E residae): Sri Lanka; social species in communal sheet web (Bradoo 1980). Before tests we removed all S. sarasinorum except one individual.

Web-building spiders generally rely on acute sensitivity to vibrations instead of vision for perceiving objects in their webs. Compared to salticid eyes, the eyes of the spiders that we used as prey are simple and not capable of acute vision (Homann 1971).
As in previous studies of salticid predatory behaviour (e.g. Jackson \& Wilcox 1990), we defined four prey sizes by the approximate ratio of prey to predator body volume: very small prey (0.01:1), small prey $(0.05: 1)$, medium prey $(1: 1)$ and large prey (2:1).

\section{BASIC SM OKESCREEN EXPERIMENTS}

\section{$M$ ethods}

We began each test by introducing P ortia onto the web of a prey species. Introduction was done by holding Portia's cage close to a prey's web and allowing Portia to leave its cage voluntarily and enter the web. Five minutes after the Portia had fixated visually on the prey and was stalking it, we started a timer that continuously indicated 30-s test segments and 90 -s inter-test segments. D uring an experimental test segment we 'disturbed' the web with either wind or a shaking magnet that simulated struggling prey. During a control test segment we did not disturb the web.

Each test included five experimental and five control test segments, in random order. F or each test segment we recorded how far Portia moved. For these recordings, we did not count pivoting in place, but recorded only the distance that the midpoint of the body moved. A II distances are accurate to the nearest millimetre. Because the absolute distances that P ortia travelled were not relevant to the questions we addressed, we only analysed the relative distances travelled during disturbance versus non-disturbance. U nless otherwise stated, a test ended either when Portia or the prey left the web, or $30 \mathrm{~min}$ elapsed. We also established a rule that a test would have ended when a prey caught Portia, but this never happened.

Some of the prey species we used had specialized patterns of defence. If, during a test, one of these spiders performed one of these specialized behaviour patterns, we cancelled the test. A Iso, if Portia groomed during a test, we terminated the test, then restarted it 30 min later. If Portia had one or more legs on a support at the edge of a web, we considered it to be out of the web, even if some legs were on the web. In certain special tests (called 'position tests'), we wanted to look specifically at whether P ortia used opportunistic smokescreen behaviour even when some or all of its legs were off the web. To obtain these data, we relaxed the standard rule that P ortia had to have all of its 
T able I. M ean ( $\pm \mathrm{SD}$ ) distance $(\mathrm{mm})$ moved by male and female juveniles and adult females (data pooled) of four species of Portia, and three populations of $\mathrm{P}$. fimbriata, in response to Badumna longinquus, in the presence and absence of wind disturbance

\begin{tabular}{|c|c|c|c|c|c|c|c|}
\hline & $\begin{array}{c}\text { Wind } \\
\text { disturbance }\end{array}$ & $\begin{array}{c}\text { Portia } \\
\text { fimbriata } \\
(\mathrm{NT})(9)\end{array}$ & $\begin{array}{c}\text { P ortia } \\
\text { fimbriata } \\
\text { (Q) (12) }\end{array}$ & $\begin{array}{c}\text { Portia } \\
\text { fimbriata } \\
(\mathrm{SL})(7)\end{array}$ & $\begin{array}{c}\text { P ortia } \\
\text { labiata } \\
\text { (9) }\end{array}$ & $\begin{array}{c}\text { Portia } \\
\text { africana } \\
(7)\end{array}$ & $\begin{array}{c}\text { Portia } \\
\text { shultzi } \\
\text { (7) }\end{array}$ \\
\hline Badumna longinquus & $\begin{array}{l}\text { Present } \\
\text { A bsent }\end{array}$ & $\begin{array}{c}33 \pm 16 \\
10 \pm 11 \\
*\end{array}$ & $\begin{array}{r}32 \pm 12 \\
6 \pm 5 \\
* *\end{array}$ & $\begin{array}{c}39 \pm 19 \\
15 \pm 8 \\
*\end{array}$ & $\begin{array}{c}25 \pm 16 \\
11 \pm 9 \\
*\end{array}$ & $\begin{array}{c}40 \pm 18 \\
9 \pm 3 \\
*\end{array}$ & $\begin{aligned} 32 & \pm 20 \\
9 \pm & 5 \\
* & \end{aligned}$ \\
\hline
\end{tabular}

$\mathrm{N}$ umber of tests is in parentheses. P ortia size relative to prey size was always 1:1. D ata analysis: Wilcoxon tests on distance moved by Portia during experimental test segments subtracted from distance moved during control test segments. N ull hypothesis: distance moved in the two types of test segments are equal. Portia used smokescreen behaviour if $\mathrm{P}<0.05$ (see text).

NT: N orthern Territory, A ustralia; Q: Queensland, A ustralia; SL: Sri Lanka populations.

$* P<0.05 ; * * P<0.005$.

legs on the silk during the test; then we used only those test segments in which the Portia spent five experimental and five control test segments with either all or some legs off the silk. For any one type of test, we used no Portia more than once, although we used some individuals in two or more different types of test. We tested each individual only once per day.

\section{Disturbances}

To make wind disturbance, we used a small electric motor that whirled a model airplane propeller positioned vertically $20 \mathrm{~cm}$ from Portia. 'W eak' wind was $15-20 \mathrm{~cm} / \mathrm{s}$, and 'strong' wind was $30-40 \mathrm{~cm} / \mathrm{s}$. We simulated the struggling of insect prey on the web by gluing a samariumcobalt magnet to a 4-mm-square $\times 2$-mm-thick piece of cork, adhering the cork to a web, then shaking the web by vibrating the cork with a $20 \mathrm{~Hz}$ sine wave (a major frequency found in many prey species of insects: R. S. Wilcox \& R. R. Jackson, unpublished data) played through a power generator into a coil of magnet wire held near the cork (see Wilcox \& K ashinsky 1980). Weak magnet 'struggles' oscillated the cork up and down about $2 \mathrm{~mm}$, strong struggles about $5 \mathrm{~mm}$. U nless stated otherwise, all wind and magnet tests reported here were 'weak'. Prey spiders were habituated to the magnet signal for $5 \mathrm{~min}$ beforea test so they would not attack the magnet during the test.

\section{D ata analysis}

For most types of tests, our interest centred on the differences in distance that Portia moved during experimental versus control test segments. We analysed this difference by using Wilcoxon matched-pairs signed-rank tests under the null hypothesis that distances moved during experimental and control test segments were equal. We found no evidence of differences in test results for age or sex classes; therefore, data for these classes were pooled unless stated otherwise.

D uring standard tests, P ortia might be oriented in a variety of different directions relative to the prey spider. To determine whether Portia's orientation affected whether it used opportunistic smokescreen behaviour, we defined three orientations: (1) directly towards the prey, (2) approximately $90^{\circ}$ away from the prey and (3) approximately $180^{\circ}$ away from the prey. $N$ ext, we tagged all tests in which Portia faced in each orientation in at least one experimental and one control test interval. To qualify, the P ortia had to face in the specified orientation for the entire test segment. F or each tagged test, we randomly chose one experimental and one control test segment with Portia oriented as specified. Pooling data from each appropriate test generated a data set for each orientation, which consisted of an experimental test segment paired with its control segment. These data sets differed from the previous standard test sets because the previous data pairs were sums from five experimental and five control test segments per Portia.

\section{R esults}

The results from the standard experimental procedure using wind and magnet disturbance 
Table II. M ean $( \pm \mathrm{SD})$ distance $(\mathrm{mm})$ moved by male and female juveniles and adult females (data pooled) of P ortia (Queensland) in response to 9 prey species of varying size, in the presence and absence of wind disturbance

\begin{tabular}{|c|c|c|c|c|c|}
\hline \multirow[b]{2}{*}{ Prey species } & \multirow{2}{*}{$\begin{array}{c}\text { Wind } \\
\text { disturbance }\end{array}$} & \multicolumn{4}{|c|}{ Predator: prey body size } \\
\hline & & 0.1 & 0.5 & 1.0 & 2.0 \\
\hline A rgiope appensa & $\begin{array}{l}\text { Present } \\
\text { A bsent }\end{array}$ & - & $\begin{array}{c}13 \pm 3 \\
3 \pm 2 \\
*(12)\end{array}$ & $\begin{array}{r}20 \pm 11 \\
7 \pm 5 \\
* * *(35)\end{array}$ & - \\
\hline A rgyrodes flavipes & $\begin{array}{l}\text { Present } \\
\text { A bsent }\end{array}$ & - & $\begin{array}{l}8 \pm 2 \\
3 \pm 3 \\
*(8)\end{array}$ & $\begin{array}{c}6 \pm 3 \\
2 \pm 1 \\
* * *(12)\end{array}$ & - \\
\hline A chaeranea sp. & $\begin{array}{l}\text { Present } \\
\text { A bsent }\end{array}$ & $\begin{array}{c}13 \pm 2 \\
7 \pm 4 \\
*(7)\end{array}$ & $\begin{array}{c}15 \pm 6 \\
10 \pm 2 \\
*(7)\end{array}$ & $\begin{array}{l}33 \pm 13 \\
10 \pm 7 \\
* * *(25)\end{array}$ & $\begin{array}{c}19 \pm 11 \\
4 \pm 3 \\
*(6)\end{array}$ \\
\hline Badumna longinquus & $\begin{array}{l}\text { Present } \\
\text { A bsent }\end{array}$ & $\begin{array}{r}23 \pm 8 \\
9 \pm 5 \\
*(7)\end{array}$ & $\begin{array}{l}21 \pm 10 \\
7 \pm 7 \\
*(6)\end{array}$ & $\begin{array}{r}32 \pm 12 \\
6 \pm 5 \\
* * *(12)\end{array}$ & $\begin{array}{r}26 \pm 18 \\
6 \pm 6 \\
*(8)\end{array}$ \\
\hline H ygropoda dolomedes & $\begin{array}{l}\text { Present } \\
\text { A bsent }\end{array}$ & $\begin{array}{r}11 \pm 2 \\
4 \pm 1 \\
*(6)\end{array}$ & $\begin{array}{c}13 \pm 6 \\
5 \pm 5 \\
*(8)\end{array}$ & $\begin{array}{r}15 \pm 8 \\
6 \pm 3 \\
*(11)\end{array}$ & $\begin{array}{c}11 \pm 6 \\
5 \pm 3 \\
*(8)\end{array}$ \\
\hline Philopoella variabilis & $\begin{array}{l}\text { Present } \\
\text { A bsent }\end{array}$ & $\begin{array}{l}23 \pm 11 \\
12 \pm 6 \\
* *(21)\end{array}$ & $\begin{array}{r}16 \pm 16 \\
7 \pm 4 \\
*(10)\end{array}$ & $\begin{array}{r}8 \pm 4 \\
4 \pm 3 \\
* * *(22)\end{array}$ & - \\
\hline Pholcus phalangioides & $\begin{array}{l}\text { Present } \\
\text { A bsent }\end{array}$ & - & - & $\begin{array}{l}28 \pm 15 \\
10 \pm 6 \\
* * *(29)\end{array}$ & - \\
\hline Stegodyphus sarasinorum & $\begin{array}{l}\text { Present } \\
\text { A bsent }\end{array}$ & - & - & $\begin{array}{c}28 \pm 8 \\
10 \pm 5 \\
* * *(12)\end{array}$ & - \\
\hline Zosis geniculatus & $\begin{array}{l}\text { Present } \\
\text { A bsent }\end{array}$ & $\begin{array}{c}27 \pm 18 \\
11 \pm 5 \\
*(7)\end{array}$ & $\begin{array}{l}20 \pm 7 \\
10 \pm 6 \\
* *(9)\end{array}$ & $\begin{array}{r}30 \pm 13 \\
8 \pm 6 \\
* * *(27)\end{array}$ & $\begin{array}{c}17 \pm 7 \\
4 \pm 4 \\
*(8)\end{array}$ \\
\hline
\end{tabular}

$-:$ : ata were not collected. $N$ umber of tests is in parentheses. $P$ ortia size relative to prey size was always 1:1. D ata analysis: Wilcoxon tests on distance moved by Portia during experimental test segments subtracted from distance moved during control test segments. Null hypothesis: distance moved in the two types of test segments are equal. $\mathrm{P}$ ortia used smokescreen behaviour if $\mathrm{P}<0.05$ (see text).

$* \mathrm{P}<0.05 ; * * \mathrm{P}<0.01 ; * * * \mathrm{P}<0.005$.

showed that Portia opportunistically capitalized on background noise as a smokescreen against all 10 prey species of spider we used. Portia moved significantly further during experimental test segments in which there was disturbance than during control test segments in which there was no disturbance (see Tables I-V). These results were true for male and female juveniles and adult females of each of the four species of Portia, including all three populations of $P$. fimbriata that we tested (Tablel), for a wide variety of sizes of prey species (Table II), and for adult males of three species of
Portia, including two populations of $\mathrm{P}$. fimbriata (Table III).

Disturbance using the magnet gave the same results as disturbance using wind for $P$. fimbriata and P. labiata, against a variety of prey species (Table IV). P ortia also used opportunistic smokescreen behaviour while oriented in different directions relative to the prey (Table $\mathrm{V}$ ). Because Portia often does not take the shortest, most direct, route towards a spider and may face in various orientations when stalking a spider (Jackson \& Hallas 1986), these orientations 
Table III. M ean ( $\pm \mathrm{sD})$ distance $(\mathrm{mm})$ moved by adult males of three species of Portia in response to three pey species, in the presence and absence of wind disturbance

\begin{tabular}{|c|c|c|c|c|c|}
\hline \multirow[b]{2}{*}{ Prey species } & \multirow{2}{*}{$\begin{array}{c}\text { Wind } \\
\text { disturbance }\end{array}$} & \multicolumn{2}{|c|}{ P. fimbriata } & \multirow[b]{2}{*}{ P. labiata } & \multirow[b]{2}{*}{ P. schultzi } \\
\hline & & (Q) & $(\mathrm{NT})$ & & \\
\hline Achaeranea sp. & $\begin{array}{l}\text { Present } \\
\text { A bsent }\end{array}$ & $\begin{array}{c}42 \pm 15 \\
30 \pm 24 \\
*(11)\end{array}$ & $\begin{array}{c}50 \pm 15 \\
28 \pm 17 \\
*(6)\end{array}$ & $\begin{array}{c}51 \pm 26 \\
23 \pm 14 \\
*(11)\end{array}$ & $\begin{array}{c}30 \pm 13 \\
18 \pm 13 \\
*(7)\end{array}$ \\
\hline Badumna longinquus & $\begin{array}{l}\text { Present } \\
\text { A bsent }\end{array}$ & $\begin{array}{l}47 \pm 29 \\
24 \pm 25 \\
\text { NS (5) } \\
P=0.28\end{array}$ & & - & - \\
\hline Z osis genicularis & $\begin{array}{l}\text { Present } \\
\text { A bsent }\end{array}$ & $\begin{array}{l}35 \pm 12 \\
14 \pm 5 \\
*(6)\end{array}$ & & - & - \\
\hline $\begin{array}{l}\text { A Il prey species } \\
\text { (pooled data) }\end{array}$ & $\begin{array}{l}\text { Present } \\
\text { A bsent }\end{array}$ & $\begin{array}{c}41 \pm 19 \\
22 \pm 18 \\
*(16)\end{array}$ & & & \\
\hline
\end{tabular}

$-: D$ ata were not collected. $N$ umber of tests is in parentheses. P ortia size relative to prey size was always 1:1. D ata analysis: Wilcoxon tests on distance moved by P ortia during experimental test segments subtracted from distance moved during control test segments. N ull hypothesis: distance moved in the two types of test segments are equal. Portia used smokescreen behaviour if $\mathrm{P}<0.05$ (see text). Q: Queensland; NT; N orthern Territory, A ustralia.

$* \mathrm{P}<0.05$; Ns: not significant.

Table IV. M ean ( $\pm \mathrm{sD})$ distance $(\mathrm{mm})$ moved by male and female juveniles and adult females (data pooled) of P ortia fimbriata and P. labiata in response to six prey species, in the presence and absence of magnet disturbance

\begin{tabular}{|c|c|c|c|}
\hline Prey species & $\begin{array}{c}\text { M agnet } \\
\text { disturbance }\end{array}$ & P. fimbriata & P. labiata \\
\hline A rgiope appensa & $\begin{array}{l}\text { Present } \\
\text { A bsent }\end{array}$ & $\begin{array}{r}16 \pm 7 \\
8 \pm 5 \\
* *(16)\end{array}$ & - \\
\hline A chaearanea sp. & $\begin{array}{l}\text { Present } \\
\text { A bsent }\end{array}$ & $\begin{array}{c}39 \pm 13 \\
16 \pm 12 \\
*(8)\end{array}$ & - \\
\hline Badumna longinquus & $\begin{array}{l}\text { Present } \\
\text { A bsent }\end{array}$ & $\begin{array}{c}35 \pm 13 \\
10 \pm 9 \\
*(9)\end{array}$ & $\begin{array}{c}36 \pm 17 \\
16 \pm 7 \\
*(6)\end{array}$ \\
\hline Z osis genicularis & $\begin{array}{l}\text { Present } \\
\text { A bsent }\end{array}$ & $\begin{array}{r}31 \pm 35 \\
14 \pm 10 \\
*(20)\end{array}$ & $\begin{array}{c}44 \pm 12 \\
9 \pm 4 \\
*(8)\end{array}$ \\
\hline H ygropoda dolomedes & $\begin{array}{l}\text { Present } \\
\text { A bsent }\end{array}$ & $\begin{array}{c}23 \pm 7 \\
4 \pm 2 \\
*(7)\end{array}$ & - \\
\hline Philoponella variabilis & $\begin{array}{l}\text { Present } \\
\text { A bsent }\end{array}$ & $\begin{array}{l}8 \pm 3 \\
3 \pm 2 \\
*(7)\end{array}$ & - \\
\hline
\end{tabular}

$-: \mathrm{D}$ ata were not collected. $\mathrm{N}$ umber of tests is in parentheses. P ortia size relative to prey size was 1:0.5-1. Data analysis: Wilcoxon tests on distance moved by Portia during experimental test segments subtracted from distance moved during control test segments. N ull hypothesis: distance moved in the two types of test segments are equal. Portia used smokescreen behaviour if $\mathrm{P}<0.05$ (see text).

$* \mathrm{P}<0.05 ; * * \mathrm{P}<0.005$. 
Table V. M ean ( $\pm \mathrm{SD}$ ) distance $(\mathrm{mm})$ moved by male and female juveniles and female adults of Portia in response to prey spiders, in the presence and absence of wind and magnet disturbance, in standard tests and position tests conducted to determine whether $P$ ortia's orientation relative to its prey affects Portia's inclination to use opportunistic smokescreen behaviour

\begin{tabular}{|c|c|c|c|}
\hline \multirow[b]{2}{*}{ Portia } & \multirow{2}{*}{$\begin{array}{l}\text { D isturbance } \\
\text { present/absent }\end{array}$} & \multicolumn{2}{|c|}{ D isturbance } \\
\hline & & Wind & M agnet \\
\hline \multicolumn{4}{|l|}{0 rientation } \\
\hline F acing directly towards prey & $\begin{array}{l}\text { Present } \\
\text { A bsent }\end{array}$ & $\begin{array}{c}5 \pm 4 \\
1 \pm 2 \\
* *(361)\end{array}$ & $\begin{array}{l}5 \pm 4 \\
1 \pm 2 \\
* *(70)\end{array}$ \\
\hline F acing $90^{\circ}$ away from prey & $\begin{array}{l}\text { Present } \\
\text { A bsent }\end{array}$ & $\begin{array}{r}8 \pm 5 \\
4 \pm 4 \\
* *(246)\end{array}$ & $\begin{array}{l}8 \pm 6 \\
1 \pm 2 \\
*(38)\end{array}$ \\
\hline Facing $180^{\circ}$ away from prey & $\begin{array}{l}\text { Present } \\
\text { A bsent }\end{array}$ & $\begin{array}{c}10 \pm 7 \\
4 \pm 4 \\
* *(71)\end{array}$ & $\begin{array}{c}12 \pm 22 \\
7 \pm 10 \\
\text { NS P }=0.09(19)\end{array}$ \\
\hline \multicolumn{4}{|l|}{ Position } \\
\hline Completely in web & $\begin{array}{l}\text { Present } \\
\text { A bsent }\end{array}$ & $\begin{array}{l}26 \pm 16 \\
10 \pm 9 \\
* *(370)\end{array}$ & $\begin{array}{c}32 \pm 23 \\
10 \pm 8 \\
*(59)\end{array}$ \\
\hline Completely off web, on solid substrate & $\begin{array}{l}\text { Present } \\
\text { A bsent }\end{array}$ & $\begin{array}{l}5 \pm 4 \\
5 \pm 4 \\
*(18)\end{array}$ & - \\
\hline
\end{tabular}

D ata are pooled from all species and sex-age classes, against a wide variety of prey species and prey sizes. - : D ata were not collected. N umber of tests is in parentheses. Data analysis: Wilcoxon tests on distance moved by Portia during experimental test segments subtracted from distance moved during control test segments. N ull hypothesis: distance moved in the two types of test segments are equal. Portia used smokescreen behaviour if $\mathrm{P}<0.05$ (see text).

$* P<0.01 ; * * P<0.001$; NS: not significant.

represent normal predatory behaviour of Portia. P ortia used smokescreen behaviour not only when in a web, but also when completely off a web, on a solid substrate beside the web (T able V).

\section{ARTIFICIAL PLAYBACK CONTROL}

\section{M ethods}

To control for the artificiality of our wind and magnet playback procedure, we examined whether P ortia would respond to background noise made by struggling insects in the same way as it re sponded to wind and magnet playbacks. We put a locust, Locusta migratoria, and a prey spider, Stegodyphus sarasinorum, in a web, then induced the locust to struggle by brushing it lightly with a bristle. We discarded tests in which a locust struggled spontaneously. Otherwise, the methods in these tests were the same as in standard tests.

\section{Results}

When locusts were struggling in a web that also contained a prey spider, P ortia performed smokescreen behaviour in synchrony with the insect's struggling noise, while always stalking the spider rather than the insect (W ilcoxon: $N=11, P<0.005$; disturbance, $\bar{X} \pm \mathrm{SD}=9 \pm 4 \mathrm{~mm}$; non-disturbance, $4 \pm 3 \mathrm{~mm}$ ).

\section{CIRCUM STANCES IN WHICH}

\section{SM OKESCREEN BEHAVIOUR IS NOT USED}

We conducted a variety of tests to examine the circumstances under which Portia does not use smokescreen behaviour. We predicted that if smokescreen behaviour is used against dangerous prey that could potentially capture Portia, or against prey that could escape or use defensive 
measures if they detected Portia, then Portia would restrict the use of smokescreen behaviour to circumstances in which dangerous or easily frightened prey were present (e.g. other spiders). W e therefore conducted a series of experiments in which non-spider prey were used, all of which Portia has previously been observed to attack in nature (J ackson \& Blest 1982). We predicted that Portia would not use smokescreen behaviour when approaching these prey, all of which were defenceless and unable to flee.

\section{M ethods}

We conducted standard smokescreen experiments, with the following conditions for Portia: (1) alone in a bare cage, with no web present, (2) alone in its own web, (3) alone in a vacant alien web, (4) alone in an alien web, feeding on a spider but with no other spider present; alone in an alien web, with (5) egg sacs, (6) a wrapped-up insect or (7) a live moth present. $N$ one of these first seven prey are spiders, in contrast to the following two circumstances, which were: (8) Portia in its own web, stalking prey spiders and (9) Portia in a $P$ hiloponella variabilis web, eating a $P$. variabilis and simultaneously stalking another $P$. variabilis.

\section{R esults}

As predicted, P ortia did not show smokescreen behaviour when no prey were present or when stalking non-spider prey, and did show this behaviour when spider prey were present (Table VI). $P$ ortia accurately identified egg sacs and insects (a noctuid moth), and it used smokescreen behaviour when in its own web and pursuing a spider. Thus Portia was not inhibited from smokescreen behaviour by being in its own web. $\mathrm{N}$ or does feeding itself inhibit Portia's smokescreen behaviour, because Portia used smokescreen behaviour not only when feeding on one spider but also when pursuing another spider in a web (T able VI).

\section{SM OKESCREEN BEHAVIOUR IS A PREDATORY TACTIC}

\section{M ethods}

If opportunistic smokescreen behaviour is indeed a predatory tactic, we might expect $\mathrm{P}$ ortia to attack and catch its prey more often when a disturbance is present than when it is absent. We went through the transcripts of standard tests and tagged all tests in which Portia attacked the prey spider, pooling data from tests with wind and with magnets.

\section{R esults}

Of 16 instances in which P ortia caught prey during the test, there were nine instances of prey capture during experimental test segments, but only one during a control test segment, resulting in a significant difference between the experimental and control tests (goodness-of-fit test, null hypothesis of equal capture frequency in experimental and control: $\left.\chi^{2}=4.900, \mathrm{P}<0.05\right)$. Six other captures were during intervals between test segments. The results supported the prediction that Portia catches prey more often during disturbances than at other times.

These data from standard tests came from a small sample size, because Portia did not often catch prey during the short standard tests. Therefore we conducted additional tests to gather more data, and specifically to investigate the relationship between prey capture and disturbances.

\section{M ethods}

For these tests, we used Z. genicularis. Test methods were as in the standard tests with wind except for the following modifications. We used only one test segment per test instead of 10, which could last up to $4 \mathrm{~h}$. B efore starting the test, we waited until Portia was within five body lengths of the $Z$. genicularis, then waited another $1,2,3,4$ or 5 min (decided randomly), after which we conducted either an experimental or a control test segment. We cancelled the test if (1) P ortia failed to get to within five body lengths of the $Z$. genicularis within $4 \mathrm{~h}$ after entering the web, (2) P ortia failed to stay within five body lengths of the $Z$. genicularis during the interval between approaching within five body lengths and the start of the test segment, or (3) if $P$ ortia attacked the $Z$. genicularis during the waiting interval. If a test was cancelled, we made another attempt with the same Portia on the next day or on each successive day until we obtained a successful test. We used each individual P ortia in a pair of tests, usually on successive days, with the experimental test segment on one day and the control segment on the other day (order decided randomly). A II tests were with male and female juveniles and adult females of P. fimbriata, and Portia 
Table VI. M ean ( $\pm \mathrm{sD}$ ) distance $(\mathrm{mm})$ moved by male and female juveniles and adult females (data pooled) of three species of P ortia in response to a variety of conditions, in the presence and absence of wind (W) and magnet (M) disturbance

\begin{tabular}{|c|c|c|c|c|}
\hline Condition & $\begin{array}{l}\text { Disturbance } \\
\text { present/absent }\end{array}$ & P. fimbriata (Q) & P. labiata & P. schultzi \\
\hline A lone in bare cage & $\begin{array}{l}\text { Present } \\
\text { A bsent }\end{array}$ & $\begin{array}{c}25 \pm 16 \\
30 \pm 19 \\
N S P=0.39 \\
(20)(W)\end{array}$ & - & - \\
\hline A lone in its own web & $\begin{array}{l}\text { Present } \\
\text { A bsent }\end{array}$ & $\begin{array}{c}8 \pm 6 \\
5 \pm 5 \\
\mathrm{NS} P=0.07 \\
(12)(W)\end{array}$ & $\begin{aligned} & 6 \pm 5 \\
& 11 \pm 9 \\
& \text { NS P }=0.053 \\
&(12)(W)\end{aligned}$ & $\begin{aligned} 3 & \pm 5 \\
6 & \pm 7 \\
\text { NS } P & =0.18 \\
(5) & (W)\end{aligned}$ \\
\hline & $\begin{array}{l}\text { Present } \\
\text { A bsent }\end{array}$ & $\begin{array}{c}23 \pm 21 \\
33 \pm 29 \\
\mathrm{NS} P=0.29 \\
(14)(M)\end{array}$ & & \\
\hline In vacant Badumna longinquus web & $\begin{array}{l}\text { Present } \\
\text { A bsent }\end{array}$ & $\begin{array}{c}15 \pm 13 \\
17 \pm 13 \\
N S P=0.38 \\
(17)(W)\end{array}$ & $\begin{aligned} 12 & \pm 9 \\
19 & \pm 18 \\
\mathrm{NS} P & =0.13 \\
(17)(\mathrm{W}) & \\
10 & \pm 11 \\
17 & \pm 21 \\
\mathrm{NS} P & =0.42 \\
(14) & (\mathrm{M})\end{aligned}$ & - \\
\hline \multicolumn{5}{|l|}{$\begin{array}{l}\text { A lone in alien web, eating a spider } \\
\text { A lien webs }\end{array}$} \\
\hline Badumna longinquus & $\begin{array}{l}\text { Present } \\
\text { A bsent }\end{array}$ & $\begin{array}{c}5 \pm 8 \\
8 \pm 8 \\
\text { NS } P=0.58 \\
(7)(W)\end{array}$ & - & - \\
\hline A chaeranea sp. & $\begin{array}{l}\text { Present } \\
\text { A bsent }\end{array}$ & $\begin{array}{c}9 \pm 11 \\
7 \pm 7 \\
\text { NS } P=0.42 \\
\text { (9) }(W)\end{array}$ & - & - \\
\hline \multicolumn{5}{|l|}{$\begin{array}{l}\text { In alien web, stalking spider egg sacs } \\
\text { Alien webs }\end{array}$} \\
\hline A chaeranea sp. & $\begin{array}{l}\text { Present } \\
\text { A bsent }\end{array}$ & $\begin{array}{c}17 \pm 7 \\
23 \pm 9 \\
\mathrm{NS} P=0.18 \\
(5)(W)\end{array}$ & $\begin{array}{c}23 \pm 8 \\
23 \pm 9 \\
\text { NS } P=0.11 \\
(4)(W)\end{array}$ & $\begin{aligned} 24 & \pm 18 \\
25 & \pm 21 \\
N S P & =0.79 \\
(3) & (W)\end{aligned}$ \\
\hline A rgiope appensa & $\begin{array}{l}\text { Present } \\
\text { A bsent }\end{array}$ & $\begin{array}{c}22 \pm 16 \\
36 \pm 33 \\
N S P=0.86 \\
(4)(W)\end{array}$ & - & - \\
\hline Z osis genicularis & $\begin{array}{l}\text { Present } \\
\text { A bsent }\end{array}$ & $\begin{array}{c}16 \pm 8 \\
16 \pm 6 \\
\text { NS P }=0.93 \\
(7)(W)\end{array}$ & $\begin{array}{c}19 \pm 9 \\
29 \pm 2 \\
\text { NS P }=0.11 \\
(4)(W)\end{array}$ & - \\
\hline $\begin{array}{l}\text { In Badumna longinquus web, stalking } \\
\text { wrapped-up fly }\end{array}$ & $\begin{array}{l}\text { Present } \\
\text { A bsent }\end{array}$ & $\begin{array}{c}12 \pm 7 \\
17 \pm 12 \\
\text { NS } P=0.17 \\
(10)(W)\end{array}$ & - & - \\
\hline $\begin{array}{l}\text { In Badumna longinquus web, stalking noctuid } \\
\text { moth }\end{array}$ & $\begin{array}{l}\text { Present } \\
\text { A bsent }\end{array}$ & $\begin{array}{c}18 \pm 14 \\
22 \pm 12 \\
\mathrm{NS} P=0.27 \\
(12)(W)\end{array}$ & - & - \\
\hline
\end{tabular}


Table VI. Continued

\begin{tabular}{|c|c|c|c|c|}
\hline Condition & $\begin{array}{l}\text { Disturbance } \\
\text { present/absent }\end{array}$ & P. fimbriata (Q) & P. labiata & P. schultzi \\
\hline \multicolumn{5}{|l|}{ In its own web, stalking prey spiders } \\
\hline P holcus phalangioides & $\begin{array}{l}\text { Present } \\
\text { A bsent }\end{array}$ & $\begin{array}{c}23 \pm 12 \\
6 \pm 5 \\
* * \\
(12)(\mathrm{W})\end{array}$ & - & - \\
\hline & $\begin{array}{l}\text { Present } \\
\text { A bsent }\end{array}$ & $\begin{array}{c}10 \pm 4 \\
4 \pm 2 \\
* \\
(12)(M)\end{array}$ & & \\
\hline A chaeranea krausi & $\begin{array}{l}\text { Present } \\
\text { A bsent }\end{array}$ & $\begin{array}{rl}11 & \pm \\
3 & \pm 2 \\
* * & 2\end{array}$ & - & - \\
\hline $\begin{array}{l}\text { In P hiloponella variabilis web, eating a } \\
\text { P. variabilis and stalking another } \\
\text { P. variabilis }\end{array}$ & $\begin{array}{l}\text { Present } \\
\text { A bsent }\end{array}$ & $\begin{array}{c}(12)(\mathrm{W}) \\
8 \pm 2 \\
0.5 \pm 1 \\
* * \\
(16)(\mathrm{W})\end{array}$ & - & - \\
\hline
\end{tabular}

Tests were designed to determine whether P ortia is selective as to when to use smokescreen behaviour. $-: D$ ata were not collected. N umber of tests is in parentheses. Portia size relative to prey size was always 1:1. Data anlysis: Wilcoxon tests on distance moved by Portia during experimental test segments subtracted from distance moved during control test segments. $\mathrm{N}$ ull hypothesis: distance moved in the two types of test segments are equal. P ortia used smokescreen behaviour if $\mathrm{P}<0.05$ (see text).

$* \mathrm{P}<0.01 ; * * \mathrm{P}<0.005$.

size relative to prey size was always 1:1. F or a pair of tests with a given $P$ ortia, there were four possible results: Portia caught the $Z$. genicularis (1) only in the experimental test, (2) only in the control test, (3) in both tests, or (4) in neither test. Being paired data, the appropriate analysis was a $\mathrm{M} \mathrm{CN}$ emar test for significance of changes, which could only be calculated on results (1) and (2).

\section{R esults}

Portia caught the $Z$. genicularis only in the experimental test nine times, only in the control once, in both no times, and in neither 58 times $(P<0.05)$, supporting the hypothesis that smokescreen behaviour is a predatory tactic. This hypothesis is further supported by results of the following study.

\section{WHY DOES THE OPPORTUNISTIC SM OKESCREEN TACTIC WORK?}

We investigated the hypothesis that Portia's smokescreen tactic works because background noise interferes with the prey's ability to detect Portia's stalking movements.

\section{C ontinuous $D$ isturbance versus $\mathrm{N}$ o $D$ isturbance: H elping Portia C apture P rey}

\section{$M$ ethods}

We tested whether we could help Portia in prey capture by providing a smokescreen disturbance that continued during the entire test. We predicted that Portia would capture prey spiders more effectively during disturbance than during no disturbance.

A ll tests were with juveniles and adult females of $P$. fimbriata, and $P$ ortia size relative to prey size was always 1:1. Prey spiders were A. appensa, $Z$. genicularis, and $B$.longinquus, each of which has readily recognizable defences against potential predators: A. appensa pumps rapidly in its orb web (Jackson et al. 1993), Z. genicularis tugs sharply on its web or leaves the web entirely, and $B$.longinquus attacks by rushing aggressively forward.

Each test lasted $60 \mathrm{~min}$, and differed from standard tests (in which experimental or control segments were brief and alternated randomly) in that each test was either an experimental condition involving continuous disturbance (wind or magnet) throughout the test, or a control 
Table VII. Effectiveness of Portia's smokescreen tactic on the webs of A rgiope appensa, Badumna longinquus and Z osis genicularis (data pooled), in the presence (experimental) and absence (control) of continuous wind disturbance

\begin{tabular}{|c|c|c|c|c|c|}
\hline & $\begin{array}{c}\text { Experimentals } \\
\text { only }\end{array}$ & $\begin{array}{l}\text { Controls } \\
\text { only }\end{array}$ & $\begin{array}{l}\text { Both } \\
\text { experimentals } \\
\text { and controls }\end{array}$ & $\begin{array}{c}\text { N either } \\
\text { experimentals } \\
\text { nor controls }\end{array}$ & $\mathrm{P} *$ \\
\hline \multicolumn{6}{|l|}{ Prey attacks P ortia or performs } \\
\hline defensive behaviour & 15 & 73 & 23 & 192 & $<0.001$ \\
\hline $\begin{array}{l}\text { Portia catches prey spider } \\
\text { P ortia walked from edge }\end{array}$ & 80 & 28 & 35 & 160 & $<0.001$ \\
\hline completely onto web & 14 & 4 & 0 & 55 & $<0.05$ \\
\hline Portia walked off web & 11 & 1 & 0 & 62 & $<0.01$ \\
\hline
\end{tabular}

$\mathrm{N}$ ull hypothesis: there is no difference in experimental versus control results. The tests used male and female juveniles and adult females of Portia fimbriata (Q). P ortia size relative to prey size $=1: 0.5$ or 1:1 (see text).

* M cN emar test.

involving no disturbance at all throughout the test. For each Portia we conducted either an experimental or a control test, on successive days (order decided randomly). The results were analysed with the $\mathrm{M} \mathrm{CN}$ emar test for significance of changes. For each Portia, the possible results from a pair of tests, with respect to prey capture and with respect to the prey's defence behaviour, could be capture or defence in (1) both tests, (2) neither test, (3) only the experimental test or (4) only the control test.

\section{R esults}

There was no evidence that the species of prey spider affected the outcome of the tests, nor that data from tests in which we used wind differed from tests in which we used magnets (tests of independence, Ns). Therefore, we pooled data from these different sets. As expected, there were significantly more instances of prey spider defence during the control tests and more instances of prey capture during the experimental tests (Table VII). Also, Portia not only entered from a solid onto webs significantly more often during disturbance, but also left webs more during disturbance (Table VII).

\section{C ontinuous $D$ isturbance versus $N o$ D isturbance: $H$ elping Prey D efend A gainst Portia}

$M$ ethods

$\mathrm{H}$ aving postulated that opportunistic smokescreen behaviour interferes with a prey spider's ability to detect approaching P ortia, we designed a procedure to help the prey spider perceive Portia's presence when Portia stalked it during background disturbance. This procedure was identical to the preceding tests with continuous wind throughout a test, except that the disturbance was perceived by Portia but did not affect the prey spider's ability to detect Portia. We achieved this by duping Portia into performing smokescreen behaviour when there was in fact no disturbance present on the web containing both Portia and the prey.

All tests were with male and female juveniles and adult females of P. fimbriata, and P ortia size relative to prey size was always $1: 1$. B efore each test, we set up two vertically oriented glassfronted cages (cages $A$ and $B$ ), one on either side of a square transparent plastic cage (cage C) ( $F$ ig. 1). C age $C$ contained a $Z$. genicularis in a horizontal web. Cages $A$ and $B$ each contained a vertical web of a Z. genicularis, but no spider, and the webs contained detritus and egg sacs. The glass sides were in place on cages $A$ and $B$ on the sides between them and cage $C$, but we removed the sides of these cages away from cage $C$. A t the start of a test, we introduced Portia into cage C. We carried out tests as in standard tests with wind, except that the wind struck only the webs in cages $A$ and $B$, the glass blocking the wind from hitting the web in the cage $C$. Thus, although Portia could not feel the wind, it could see the webs in cages $A$ and $B$, with their detritus and egg sacs moving. $\mathrm{H}$ aving two cages receive wind ensured that Portia would see the neighbouring webs blowing in the wind, regardless of its orientation on the web in cage $C$. We used strong wind to 


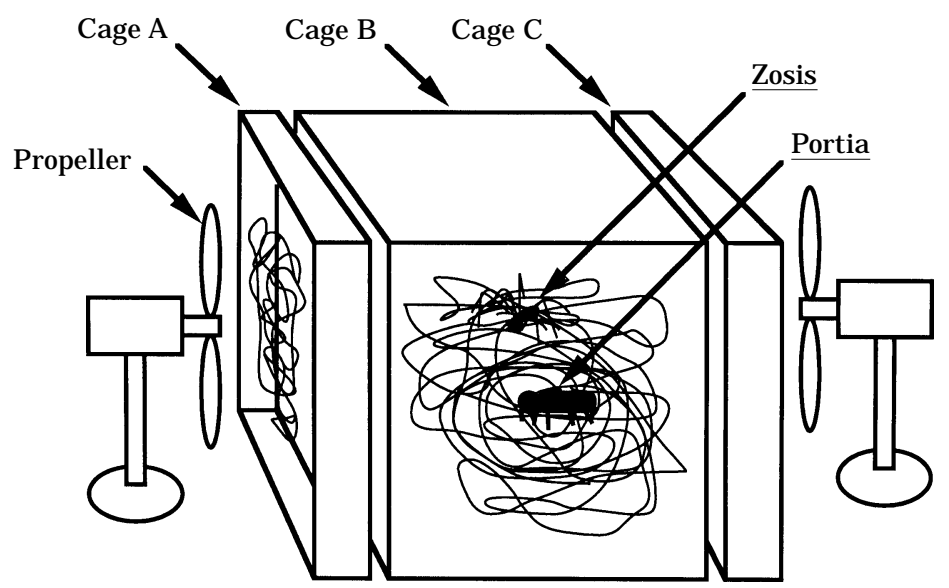

Figure 1. Experimental set-up to induce P ortia to perform smokescreen behaviour from visual stimuli only. Vertical cages $A$ and $B$ had webs of $Z$. genicularis in them, but no spiders. G lass fronts of cages A and B were removed on the sides near the propellers, but not on the sides by cage $C$, which was constructed of glass; thus the web in cage $C$ receives no wind stimulus. Square cage $C$ contained a $Z$. genicularis web with a $Z$. genicularis in it. $A$ Portia was introduced onto the web in cage $C$, and wind was blown by the propellers onto the vacant webs in cages $A$ and $B$, making egg sacs and detritus move in the webs. P ortia could not feel the wind, but saw webs in cages $A$ and $B$ moving and performed smokescreen behaviour while stalking the Z . genicularis.

make the movement of detritus and egg sacs conspicuous.

We predicted that Portia would be less successful at prey capture during these tests, and the prey spider would be more likely to perform defence behaviour, than during standard tests using wind for disturbance. We therefore used tests of independence to compare data from these tests with data from previous standard tests.

\section{R esults}

Portia responded to the sight of the winddisturbed webs with smokescreen behaviour as in standard tests, only now there was no wind to conceal Portia's movements from the $Z$. genicularis. Portia caught the $Z$. genicularis in 32 of 76 tests with continuous 'actual' wind, but in only 28 of 148 tests with continuous 'visual' wind $\left(\chi^{2}=12.61, P<0.001\right)$. $Z$ osis genicularis performed defence behaviour in 28 of 148 tests in visual wind, but in only five of 76 tests in actual wind $\left(\chi^{2}=6.09, \mathrm{P}<0.01\right)$. These results supported our prediction that smokescreen behaviour interfered with the prey spider's ability to detect the predator on the web.

\section{PORTIA'S SMOKESCREEN BEHAVIOUR: IRRITATION OR PREDATORY TACTIC?}

Our hypothesis is that Portia performs smokescreen behaviour as a predatory tactic. A $n$ alternative hypothesis, however, is that this behaviour is simply an artefact of Portia being irritated by the stimulus we used for a disturbance. We there fore evaluated how Portia responded to irritation from wind blowing on it or from a magnet vibrating its web, and predicted that Portia would be more irritated by a strong disturbance than by a weak disturbance. We therefore conducted two sets of tests comparable to previous tests with weak disturbances, only now with strong disturbance stimuli also.

\section{Portia A lone in Its $\mathbf{0}$ wn W eb}

\section{$M$ ethods}

We tested Portia's response to differences solely of disturbance intensity by first noting Portia's response when alone in its own web, thereby establishing baseline information on how Portia responds to irritation, with no other distractions. 
Table VIII. M ean ( $\pm \mathrm{sD}$ ) distance $(\mathrm{mm})$ moved by male and female juveniles and adult females of Portia fimbriata (Q) alone or in response to Badumna longinquus, in the presence and absence of wind (W) and magnet (M) disturbance, of weak and strong intensity

\begin{tabular}{|c|c|c|c|}
\hline \multirow[b]{2}{*}{ Portia } & \multirow{2}{*}{$\begin{array}{l}\text { D isturbance } \\
\text { present/absent }\end{array}$} & \multicolumn{2}{|c|}{$\begin{array}{l}\text { Wind or magnet } \\
\text { disturbance }\end{array}$} \\
\hline & & W eak & Strong \\
\hline A lone in own web & $\begin{array}{l}\text { Present } \\
\text { A bsent }\end{array}$ & $\begin{array}{c}6 \pm 5 \\
8 \pm 7 \\
\text { NS } P=0.17 \\
\text { (34) (W) }\end{array}$ & $\begin{array}{c}24 \pm 8 \\
9 \pm 6 \\
* \\
(63)(W)\end{array}$ \\
\hline & $\begin{array}{l}\text { Present } \\
\text { A bsent }\end{array}$ & $\begin{array}{c}23 \pm 21 \\
33 \pm 29 \\
\mathrm{NS} P=0.29 \\
(14)(\mathrm{M})\end{array}$ & $\begin{array}{c}44 \pm 16 \\
18 \pm 10 \\
* \\
(6)(M)\end{array}$ \\
\hline $\begin{array}{l}\text { In occupied Badumna } \\
\text { longinquus web }\end{array}$ & $\begin{array}{l}\text { Present } \\
\text { A bsent }\end{array}$ & $\begin{array}{c}33 \pm 16 \\
10 \pm 7 \\
* \\
(53)(W)\end{array}$ & $\begin{array}{c}10 \pm 6 \\
12 \pm 5 \\
\mathrm{NS} P=0.43 \\
(15)(W)\end{array}$ \\
\hline & $\begin{array}{l}\text { Present } \\
\text { A bsent }\end{array}$ & $\begin{array}{c}30 \pm 14 \\
13 \pm 8 \\
* \\
(15)(M)\end{array}$ & $\begin{array}{c}9 \pm 8 \\
7 \pm 4 \\
\text { NS } P=0.98 \\
(14)(M)\end{array}$ \\
\hline
\end{tabular}

$\mathrm{N}$ umber of tests is in parentheses. $\mathrm{P}$ ortia size relative to prey size was always 1:1. $\mathrm{D}$ ata analysis: Wilcoxon tests on distance moved by P ortia during experimental test segments subtracted from distance moved during control test segments. N ull hypothesis: distance moved in the two types of test segments are equal. P ortia used smokescreen behaviour if $P<0.05$ (see text).

$* \mathrm{P}<0.05$.

R esults

During weak wind disturbance Portia did not move more during disturbance than during nondisturbance; that is, Portia essentially ignored weak disturbance, and did not perform smokescreen behaviour. During strong disturbance, however, Portia moved significantly more during disturbance than non-disturbance (Table VIII). M oreover, during strong disturbance, Portia moved more rapidly and produced more locomotory vibrations than when performing smokescreen behaviour during weak disturbance.

\section{Portia in an $\mathbf{O}$ ccupied Alien W eb}

$M$ ethods

We next tested Portia in an alien web under strong disturbance to see whether that provoked a different response from that to weak disturbance.

\section{R esults}

From our previous studies, we knew that a weak wind disturbance stimulated P ortia in a web containing a $B$. longinquus to respond with smokescreen behaviour (Table VIII). U nder strong wind disturbance, however, P ortia showed no difference between experimental and control test segments (Table VIII). Furthermore, we did not see the unguarded style of locomotion that P ortia showed when alone in its own web and stimulated by strong disturbance (Table VIII). We concluded that Portia suppressed its irritation response to strong wind and acted cautiously in the presence of $B$. longinquus. These results support our hypothesis that smokescreen behaviour is a predatory tactic and not an irritation response when in the presence of a prey spider.

\section{DISCUSSION}

Smokescreen behaviour appears to be a means of moving in the presence of other spider species. It is probably a general behavioural characteristic of the genus Portia, because male and female juveniles, adult males and females of all four 
species and all populations of Portia tested responded with smokescreen behaviour to both wind and magnet disturbance. The behaviour seems to be effective against a wide range of spider prey species, because Portia used it when in the webs of all 10 spider prey species, and against spiders of widely different sizes within each prey species. The tests using live insects supported previous evidence that P ortia accurately discriminated between insects and spiders on the same web, and preferred spiders as prey (Jackson \& Wilcox 1993).

Portia apparently does not have to see a spider to use smokescreen behaviour effectively, because Portia performed smokescreen behaviour when at any orientation relative to the prey spiders. This behavioural pattern is likely to be related to a feature of Portia's stalking strategy: Portia sometimes shows 'detour behaviour', a behaviour previously described in jumping spiders by $\mathrm{Hill}$ (1979), in that it does not stalk directly towards a prey spider, but instead takes a circuitous route, often not looking at the prey when doing so and even going around obstacles that cut off the prey spider from view (Jackson \& Wilcox 1993; Tarsitano \& Jackson 1994).

Because P ortia attacked spider prey more often during disturbance than during non-disturbance periods, and prey spiders appeared less able to sense the presence of Portia on their webs during disturbance periods, Portia's smokescreen behaviour appears to be a genuine predatory tactic. The evidence suggests that the ploy works by interfering with the prey spiders' ability to detect Portia. Our results show that Portia uses smokescreen behaviour when entering, stalking in, and leaving webs, which makes sense from two viewpoints. First, many of Portia's spider prey are dangerous to Portia, and Portia is occasionally captured by its intended prey (e.g. Jackson \& $H$ allas 1986). Second, some of the prey spiders that Portia attacks specificially respond to the vibration patterns from Portia walking on their webs by leaving the web altogether. No other genus of spiders that we have tested has caused a prey spider species to leave its web entirely (R. S. Wilcox \& R. Jackson, unpublished data). Thus, smokescreen behaviour appears also to be a strategy to prevent prey spiders from leaving the web.

The slower, low-vibration movement that Portia showed when on a $B$. longinquus web under strong wind disturbance appears to be a sensible behaviour on Portia's part, because $B$. Ionginquus is one of the more dangerous prey Portia stalks. This interesting ability of Portia to control its irritation response to strong wind when in a dangerous situation indicates that Portia discriminates between weak and strong disturbances, and the results are consistent with our hypothesis that strong disturbance is an irritation, and weak disturbance is a cue to perform smokescreen behaviour.

P ortia's smokescreen behaviour appears similar to descriptions of certain kleptoparasitic spiders moving stealthily across their host's web towards ensnared prey when the host spider is motionless, but moving more rapidly when the host is feeding on prey or moving around on its web (A rgryodes elevatus, Theriididae: V ollrath 1979; M ysmenopsis furtiva, M ysmenidae: Coyle et al. 1991). A different but related situation is the "vibratory camouflage' displayed by certain grasshoppers to avoid capture by ctenid spiders on banana leaves (Barth et al. 1988), characterized by a slow, cautious 'vibrocryptic' gait that may be imitating the low-frequency vibrations made by wind. The opportunistic smokescreen behaviour of P ortia, in contrast, appears to capitalize on the concealing or masking effect of the wind on a prey spider's web. Although the kleptoparasitic spiders and the grasshoppers seem likely to benefit from their stealthy behaviour, experimental evidence is lacking.

There are obvious advantages for a predator that can exploit situations in which a prey's predator-detection abilities are handicapped. Predatory tactics comparable to Portia's opportunistic smokescreen behaviour, although rarely investigated, may be widespread. It would be enlightening to take a closer look, not only at other spiders, but also at other species as well. F or example, Shaller (1972) noted that lions not only hunt more often during the night, but also preferentially hunt when cloud cover suddenly obscures the moon, making the night vision of prey less effective. As another example, Brown (1980) noted that he was trained by his A pache Indian teacher to stalk game by taking advantage of background noise in the environment that would mask the sounds of his stalking. We suspect that many intriguing stories will emerge from future studies on smokescreen behaviour in various species. 


\section{ACKNOWLEDGMENTS}

We gratefully acknowledge the assistance of Alayna Wilcox in data gathering. Bill Romey, $D$ ayne Wilcox and two anonymous referees provided helpful comments on the manuscript. This study was supported by N SF grant BN S8617078, the U nited States-N ew Zealand Cooperative Science Program, and $\mathrm{N}$ ational Geographic Society grant 3226-85.

\section{REFERE NCES}

Barth, F ., Bleckmann, H ., Bohnenberger, J. \& Seyfarth, E.-A. 1988. Spiders of the genus Cupiennius Simon 1891 (A raneae, Ctenidae). II. On the vibratory environment of a wandering spider. O ecologia (B erl.), 77, 194-201.

Blest, D. 1985. Fine structure of spider photoreceptors in relation to function. In: N eurobiology of A rachnids (Ed. by F. Barth), pp. 79-102. N ew Y ork: SpringerVerlag.

Bradoo, B. L. 1980. Feeding behaviour and recruitment display in the social spider Stegodyphus sarasinorum $\mathrm{K}$ arsch (A raneae, Eresidae). Tijdschr. Entomol., 123, 89-104.

Brown, T. 1980. The Search: The Continuing Story of the Tracker. Englewood Cliffs, $\mathrm{N}$ ew J ersey: Prentice-H all.

Coyle, F. A ., O'Shields, T. C. \& Perlmutter, D. G. 1991. Observations on the behavior of the kleptoparasitic spider, M ysmenopsis furtiva (A raneae, M ysmenidae). J. A rachnol., 19, 62-66.

Curio, E. 1976. The Ethology of Predation. Berlin: Springer-Verlag.

F orster, L. 1982. Vision and prey-catching strategies in jumping spiders. A m. Scient., 70, 165-175.

H ill, D. E. 1979. Orientation by jumping spiders of the genus $\mathrm{Phidippus}$ pulcherrimus (A raneae: Salticidae) during the pursuit of prey. B ehav. Ecol. Sociobiol., 5, 301-322.

H omann, H. 1971. Die A ugen der A raneae. A natomie, Ontogenie und Bedeutung fur die Systematik (Chelicerata, A rachnida). Z. M orphol. Ö kol. Tiere, 69, 201272.

J ackson, R . R . 1992. Eight-legged tricksters, spiders that specialize in catching other spiders. BioScience, 42, 590-598.

J ackson, R. R . \& Blest, D. 1982. The biology of P ortia fimbriata, a web-building jumping spider (A raneae,
Salticidae) from Queensland: utilization of webs and predatory versatility. J . Z ool., L ond., 196, 255-293.

Jackson, R. R. \& Hallas, S. 1986. Comparative biology of Portia africana, P. albimana, P. fimbriata, P. labiata, and P. schultzi, araneophagic, webbuilding jumping spiders (A raneae, Salticidae): utilisation of webs, predatory versatility, and intraspecific interactions. N.Z. J I Z ool., 13, 423-489.

Jackson, R. R., Rowe, R. J. \& Wilcox, R. S. 1993. A ntipredator defences of Argiope appensa (A raneae, A raneidae), a tropical orb-weaving spider. J. Z ool., L ond., 229, 121-132.

J ackson, R. R. \& Wilcox, R. S. 1990. A ggressive mimicry, prey-specific predatory behaviour and predatorrecognition in the predator-prey interactions of Portia fimbriata and Euryattus sp., jumping spiders from Queensland. Behav. Ecol. Sociobiol., 26, 111119.

Jackson, R. R. \& Wilcox, R. S. 1993. Observations in nature of detouring behaviour by Portia fimbriata, a web-invading aggressive mimic jumping spider from Queensland. J . Z ool., L ond., 230, 135-139.

J ackson, R. R. \& Wilcox, R. S. 1994. Spider flexibly chooses aggressive mimicry signals for different prey by trial and error. Behaviour, 127, 21-36.

Land, M. 1985. The morphology and optics of spider eyes. In: N eurobiology of A rachnids ( $E$ d. by F. B arth), pp. 53-78. N ew Y ork: Springer-V erlag.

Lloyd, J. 1986. Firefly communication and deception: 'oh, what a tangled web'. In: Deception: Perspectives on $\mathrm{H}$ uman and N onhuman Deceit ( $\mathrm{Ed}$. by R. M itchell $\& N$. Thompson), pp. 113-128. A lbany, $\mathrm{N}$ ew $\mathrm{Y}$ ork: State U niversity of N ew Y ork Press.

M itchell, R . \& Thompson, N . 1986. Deception: Perspectives on $\mathrm{H}$ uman and $\mathrm{N}$ onhuman Deceit. A lbany, $\mathrm{N}$ ew $\mathrm{Y}$ ork: State $\mathrm{U}$ niversity of $\mathrm{N}$ ew $\mathrm{Y}$ ork Press.

Pietsch, T. \& G robecker, D. 1978. The compleat angler: aggressive mimicry in an antennariid angler fish. Science, 201, 369-370.

Shaller, G. 1972. The Serengeti Lion. Chicago: U niversity of Chicago Press.

Tarsitano, M. S. \& Jackson, R. R. 1994. Jumping spiders make predatory detours requiring movement away from prey. Behaviour, 131, 65-73.

Vollrath, F. 1979. Behaviour of the kleptoparasitic spider Argryodes elevatus (A raneae, Theridiidae). A nim. B ehav., 27, 515-521.

Wickler, W. 1968. M imicry. N ew Y ork: M CG raw-H ill.

Wilcox, R. S. \& K ashinsky, W. 1980. A computerized method of analysing and playing back vibratory signals. B ehav. M eth. Instrumn, 12, 361-363. 